\title{
J. Suwanjarat \\ Ultrastructure of the spermatogenesis of the cockle Anadara granosa L. (Bivalvia: Arcidae)
}

Received: 29 September 1998 / Received in revised form: 20 May 1999 / Accepted: 14 June 1999

\begin{abstract}
In this paper spermatogenesis and sperm ultrastructure of the cockle Anadara granosa are studied using transmission electron microscopy. The spermatocyte presents electron-dense vesicles and the arising axoneme that begins to form the flagellum. During spermatid differentiation, proacrosomal vesicles appear to migrate towards the presumptive anterior pole of the nucleus; eventually these vesicles become acrosome. The spermatozoon of Anadara granosa is of the primitive type. The acrosome, situated at the apex of the nucleus, is capshaped and deeply invaginated at the inner side. The spherical nucleus of the spermatozoon contains dense granular chromatin and shows invagination at the posterior poles. The centriole shows the classic nine triplets of microtubules. The middle piece consists of the centriolar complex surrounded by five giant mitochondria. It is shown that the ultrastructure of spermatozoa and spermiogenesis of Anadara granosa reveals a number of features that are common among bivalves.
\end{abstract}

Key words Anadara granosa - Arcidae . Spermatogenesis $\cdot$ Spermiogenesis

\section{Introduction}

The blood cockle Anadara granosa L. is a bivalve mollusc in the family Arcidae, subfamily Anadarinae. The bivalves in this family are of considerable importance as a source of cheap protein in tropical areas, especially in the Indo-Pacific region (Bardach et al. 1972). Therefore, the recognition of species in this family for aquaculture has led to investigation of their basic reproductive biology. Gonad development and spawning in bivalves of the family Arcidae have been extensively studied by light microscope (Kan-no 1963; Kim and Koo 1973; ToralBarza and Gomez 1985). Several aspects of the reproductive biology and the breeding cycle of Anadara gra-

\footnotetext{
J. Suwanjarat $(\square)$
}

Department of Biology, Faculty of Science,

Prince of Songkla University, Hat-Yai 90110 Thailand nosa in various areas have been examined (Broom 1983; Suwanjarat and Parnrong 1990). Yet the ultrastructural gametogenesis and spermatozoa of Anadara granosa have not been described and no detailed description throughout spermatogenesis has been reported at the ultrastructural level.

In the molluscan class Bivalvia the spermatozoon is the primitive type in almost all species studied (Franzen 1983; Hodgson and Bernard 1986; Dorange and Le Pennec 1989; Sousa et al. 1989). Spermatozoon morphology of bivalves is relatively constant, especially when compared with the diversity of form within other molluscan groups (Maxwell 1983). Variations in the morphology of bivalve spermatozoa are species specific, and in many cases general patterns can be distinguished among taxonomic groups (Popham et al. 1974; Hodgson and Bernard 1986). In addition, the conclusion of Hodgson and Bernard (1988) with respect to 16 species of the Patellidae that each species has a sperm with a unique morphology indicates that spermatozoa can be used as a taxonomic character. According to Franzen (1955), sperm morphology is related to fertilization biology. Sperm morphology often gives useful indications on phylogenetic problems, as several examples have shown (Baccetti and Afzelius 1976). Thus, the examination of sperm structure and morphological information are of significance in questions dealing with reproductive biology as well as in phylogeny (Baccetti and Afzelius 1976; Afzelius 1979).

In this study we describe the ultrastructural morphology of the spermatozoon and illustrate the stages of sperm formation in Anadara granosa using the transmission electron microscope. We hope that the present study will lead to a better understanding of the basic features of the different spermatogenic stages and provide useful information in determining systematic and phylogenetic relationships among the Arcidae and other Bivalvia. 
Fig. 1 Anadara granosa. Transmission electron microscope (TEM). 1 Primary spermatogonia with large nucleus $(N)$. M Mitochondria; $s c$ spermatocyte. Scale bar $2 \mu \mathrm{m} . \mathbf{2}, \mathbf{3}$ Two-nucleus stage spermatocytes. $C n$ centriole; $d$ electrondense vesicle; $M$ mitochondria; $N$ nucleus; $V$ vacuole. Scale bar $2 \mu \mathrm{m} .4$ Spermatocyte with numerous mitochondria $(M)$ and a centriole (arrow) close to the cell membrane. $n$ Nucleus. Scale bar $2 \mu \mathrm{m} .5$ Flagellum $(F)$ was present in cytoplasm of the spermatocyte. $\mathrm{cm}$ Cell membrane. Scale bar $1 \mu \mathrm{m}$
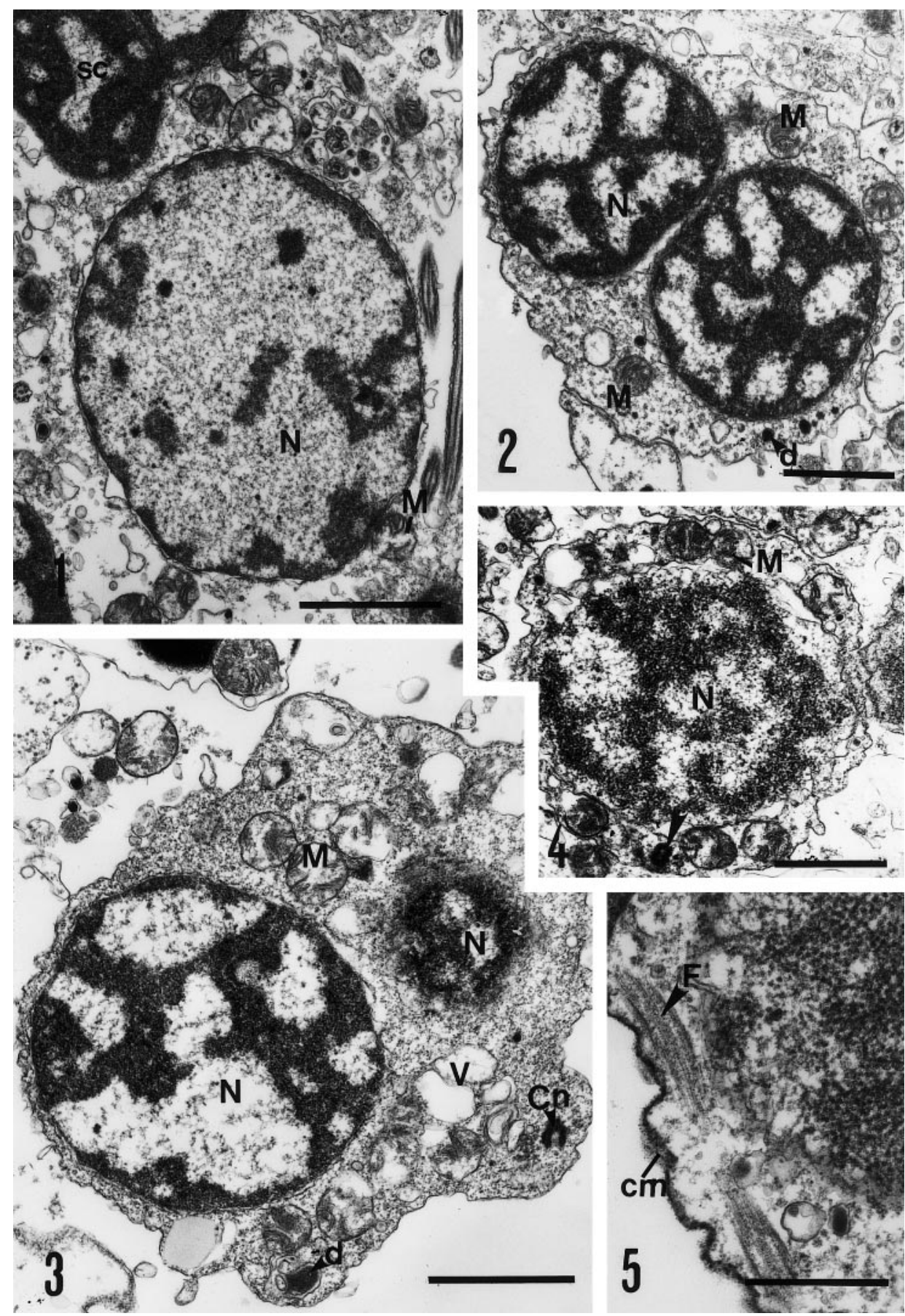

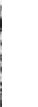

\section{Materials and methods}

Live specimens of mature Anadara granosa (30-35 mm long) were collected from the intertidal mudflat at Satun Province, on the western coast of southern Thailand, during April 1997. The specimens were transported to the laboratory at Prince of Songkla University, Hat-Yai Campus. Samples of male gonads were removed and small pieces of the gonads were fixed in $4 \%$ paraformaldehyde (phosphate buffer $\mathrm{pH} 7.3$ ) for $24 \mathrm{~h}$ at $4{ }^{\circ} \mathrm{C}$ and postfixed for $1 \mathrm{~h}$ in $1 \%$ osmium tetroxide and stained in $2 \%$ uranyl acetate for $45 \mathrm{~min}$. Specimens were dehydrated in serially graded ethanol (three changes each) for $3 \mathrm{~min}$ each wash, followed by propylene oxide (two changes) for $15 \mathrm{~min}$ each. The tissues were infiltrated in 50:50 parts propylene oxide and Epon 812, and embedded in Epon 812. Ultrathin sections were cut on Reichert-Jung ultracut $\mathrm{E}$ and mounted on copper grids, and then stained with uranyl acetate and lead citrate. The sections were observed using a Zeiss EM 9S-2 transmission electron microscope. The process of ultrathin sectioning, staining and the examination of the specimens with transmission electron microscope were carried out at the Zoological Institute, the University of Vienna, Austria. 
Fig. 2 Anadara granosa. TEM. 6 Early spermatid showing cytoplasm with numerous mitochondria $(M)$ shifted to the presumptive posterior pole of the nucleus $(N) . d$ Electrondense vesicles. Scale bar $2 \mu \mathrm{m}$. 7 Early spermatid with a flagellum $(F)$ at periphery of cell. Scale bar $2 \mu \mathrm{m} .8$ Early spermatid; electron-dense vesicles $(d)$ are randomly distributed in the cytoplasm and a few large mitochondria $(M)$ are formed. Scale bar $1 \mu \mathrm{m} . \mathbf{9}, 10$ Early spermatids. $M$ Mitochondria; $N$ nucleus; $d$ electron-dense vesicle. Scale bar $2 \mu \mathrm{m} .11$ Intermediate spermatids showing nuclear chromatin becoming condensed. $M$ Mitochondria; $N$ nucleus. Scale bar $1.5 \mu \mathrm{m} .12$, 13 Nucleus $(N)$ of intermediate spermatids is almost completely condensed and size of mitochondria $(M)$ compared to nucleus is much larger than in the early spermatid. Scale bar $1 \mu \mathrm{m}$

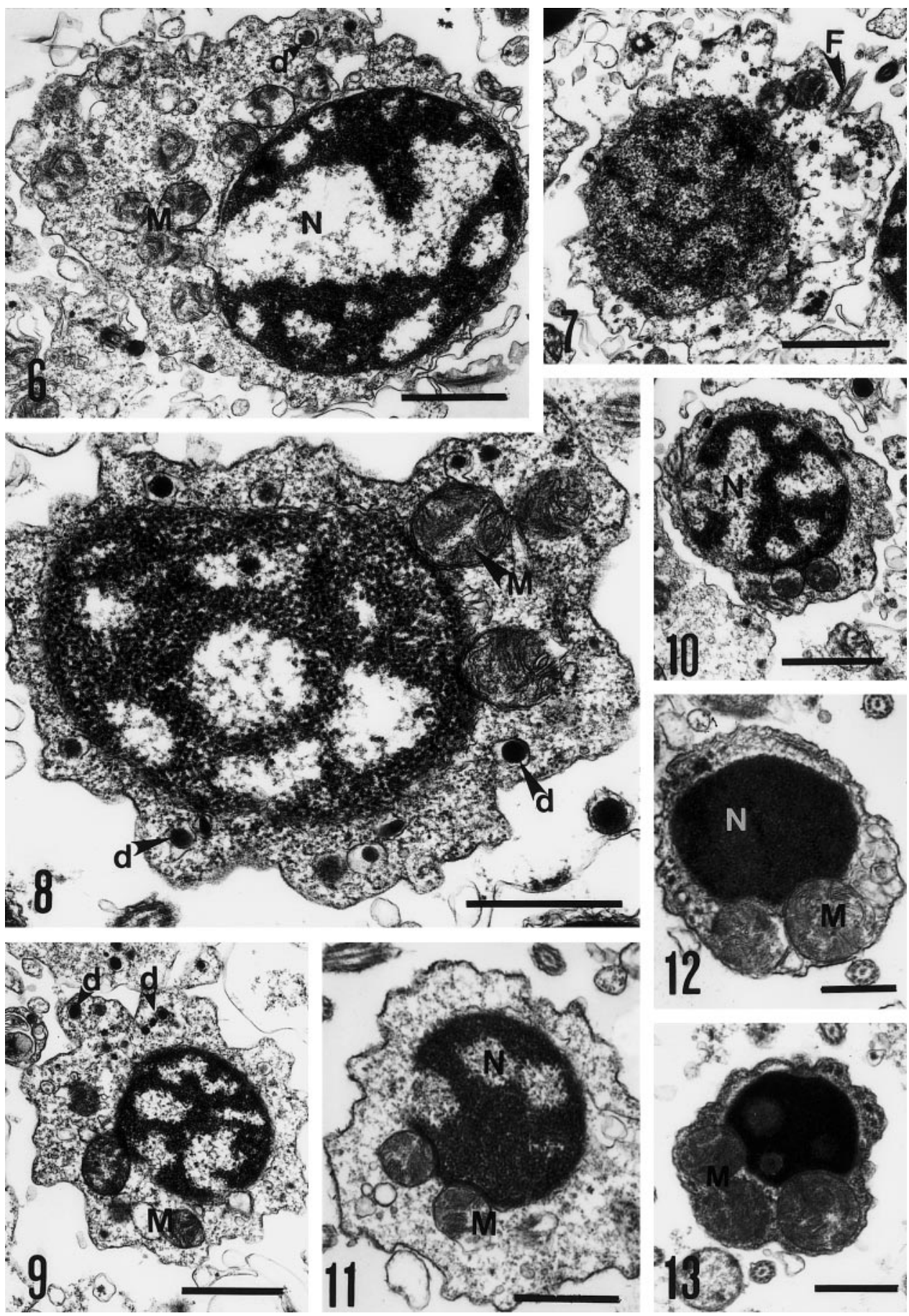

\section{Results}

Gonad of the normal, mature male Anadara granosa shows various stages of germ cells during spermatogenesis. The ultrastructure of spermatogonia, spermatocytes, spermatids and mature spermatozoa is identified and described as follows.

\section{Spermatogonia}

Spermatogonia are located at the peripheral region of the follicle. Primary spermatogonia give rise to secondary spermatogonia that have spherical or oval nuclei. The nucleus of spermatogonia is large and characterized by the presence of small patches of heterochromatin scattered throughout the nucleoplasm. The scanty cytoplasm contains few cytoplasmic organelles. The rough endoplasmic reticulum is poorly developed (Fig. 1, part 1). At the end of this stage, spermatogonia undergo mitosis and become spermatocytes. 
Fig. 3 Anadara granosa. TEM. 14 Distribution of germ cells in the lumen. $s g$ Spermatogonium; st spermatid. Scale bar $3 \mu \mathrm{m} .15$ Formation of acrosome. 15a, 15b Acrosome (ac) of late spermatid. Beneath the acrosome is the subacrosomal substance (arrow). Scale bar $0.5 \mu \mathrm{m}$.

15c Acrosome (ac) of spermatozoon. Scale bar $0.5 \mu \mathrm{m}$

16 Longitudinal section (LS) of a spermatozoon. ac Acrosome; $M$ mitochondria; $N$ nucleus; $p c$ proximal centriole. Scale bar $1 \mu \mathrm{m} .17 \mathrm{LS}$ of an invagination (arrow) in base of sperm nucleus. $M$ Mitochondria. Scale bar $0.5 \mu \mathrm{m} .18$ Transverse section (TS) of a centriole. Scale bar $0.5 \mu \mathrm{m}$. 19: LS of a flagellum. Scale bar $0.5 \mu \mathrm{m} .20 \mathrm{TS}$ of a spermatozoon midpiece; electron-dense granules (arrow) interspersed between mitochondria $(M) . F$ Flagellum. Scale bar $0.7 \mu \mathrm{m}$
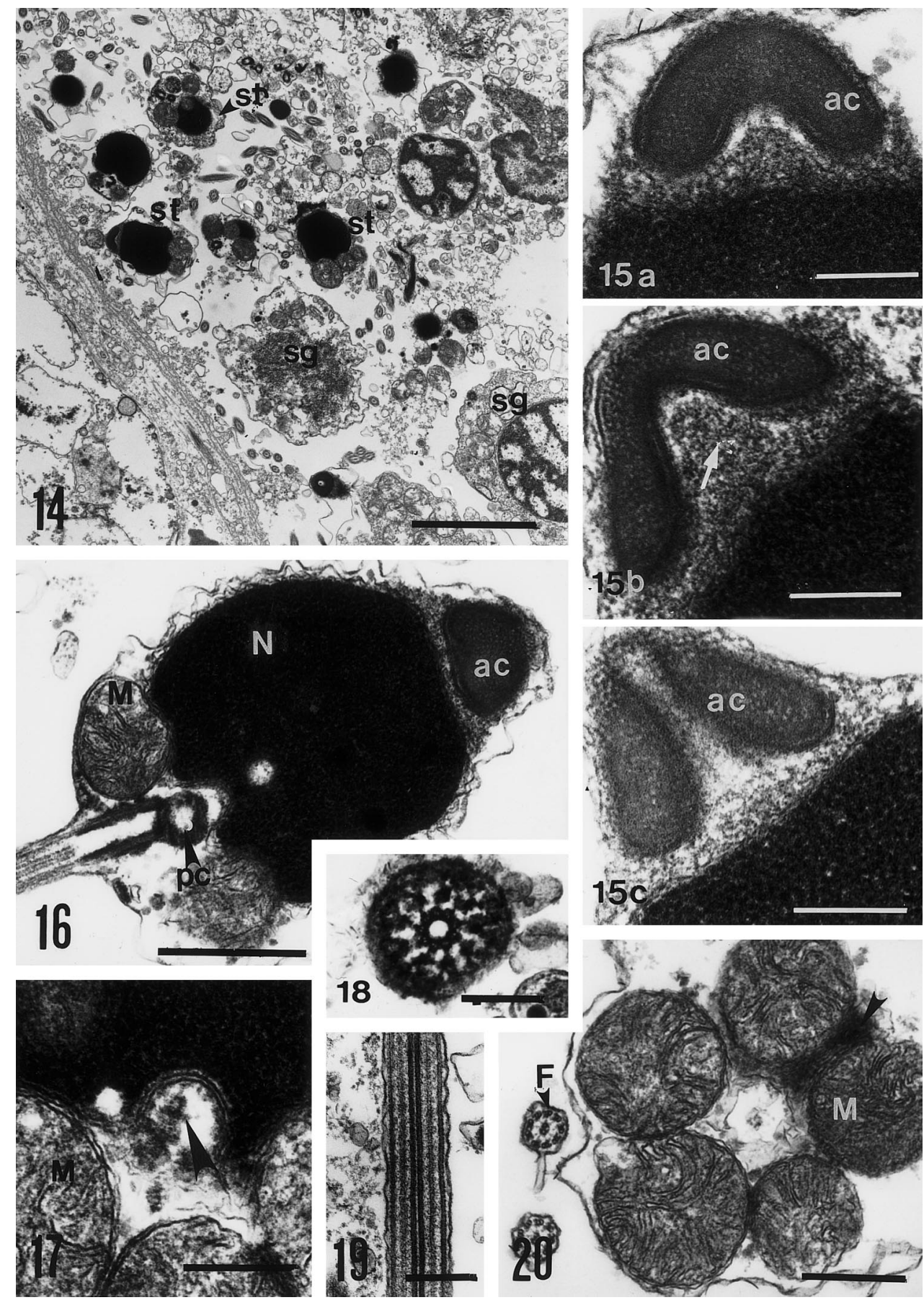

Spermatocytes

Primary spermatocytes undergo meiosis to produce secondary spermatocytes. The primary spermatocytes (Fig. 1, parts 2-4) are smaller than spermatogonia. The cellular outline of primary spermatocyte is irregular and the cytoplasmic volume has increased. In the cytoplasm of these cells, numerous glycogen-like particles are observed; several mitochondria and electron-dense vesicles are obvious and a number of vacuoles are found in some spermatocytes (Fig. 1, part 3). The flagellum begins to form at this stage. It has been found that in some sper- matocytes the flagellum is already formed and present in the cytoplasm (Fig. 1, part 5).

\section{Spermatids}

The early spermatids (Fig. 2, parts 6,7) are irregular in shape with a large spherical nucleus and nuclear chromatin begins to condense. The cytoplasm of the spermatid at this stage consists of numerous electron-dense granules which are randomly distributed and the cytoplasm is shifted to the presumptive posterior pole of the nucleus. 
The condensation of chromatin is uniform and occurs evenly throughout the nucleus. As spermiogenesis comes to an end, the chromatin undergoes progressive condensation where invagination occurs at the posterior pole of the nucleus. During the nucleus transformation (Fig. 2, parts $8-13$, Fig. 3, part 14), the spherical-shaped mitochondria which are found dispersed in the cytoplasm begin to migrate towards the basal pole of the nucleus. The mitochondria decrease in number but increase their size. These mitochondria are derived from the fusing of spermatocyte mitochondria into a number of large mitochondria with well-developed cristae. The prominent giant mitochondria begin to aggregate at the base of the nucleus of the late spermatid and eventually become closely associated with the developing flagellar axoneme. The proacrosomal vesicles with an electron-dense granule in the central core fuse to form an acrosomal vesicle. This vesicle increases in size and develops into one large acrosome (Fig. 3, part 15). The acrosome of Anadara granosa is a vesicle that covers the anterior pole of the spermatid nucleus. The inner side of the acrosome becomes concave and invaginated basally in the late spermatid (Fig. 3, part 15a). Between the acrosomal vesicle and the nucleus is dense granular material of the subacrosomal substance. At the same time as the acrosome formation is taking place, the shape of the entire sperm is changing and the differentiation of the sperm tail is occurring.

\section{Spermatozoa}

The fully mature spermatozoon of Anadara granosa consists of three distinct regions: a head, midpiece and flagellum (Fig. 3, part 16) The head region of the spermatozoon is composed of nucleus and acrosome at the most anterior. The nucleus is roughly spherical and approximately $2.3-2.4 \mu \mathrm{m}$ long and $2.5 \mu \mathrm{m}$ wide. The nuclear contents are highly electron dense and granular in texture (Fig. 3, part 16). The anterior of the nucleus, which is close to the acrosome, is flattened, whereas the posterior of the nucleus is invaginated (Fig. 3, part 17). The acrosome of Anadara granosa is membrane bounded, cap-shaped and measures $0.9 \mu \mathrm{m}$ in length and 1.2 $\mu \mathrm{m}$ in maximum diameter at the base. The acrosomal vesicle is invaginated basally and the invagination is almost as deep as the height of the acrosome (Fig. 3, part $15 \mathrm{c})$. This invagination is occupied by granular substance of subacrosomal material (Fig. 3, parts 15b,c). Posterior to the nucleus is the midpiece. This region consists of five giant, spherical mitochondria (diameter $0.9 \mu \mathrm{m}$ ) arranged in a ring with two centrioles at the center. There are some electron-dense granules interspersed between the mitochondria (Fig. 3, part 20). The cristae of each mitochondrion are well developed and randomly arranged (Fig. 3, parts 17, 20). The centrioles and flagellar apparatus are seen at the posterior end of the nucleus, with the proximal centriole close to the nucleus, while the distal centriole gives rise to the sperm flagellum. There is moderately dense material between the proxi- mal centriole and the invaginated pole of the nucleus (Fig. 3, part 17). The centrioles show the classic nine triplets of microtubules (Fig. 3, part 18) and also the microtubular arrangement of the flagellum is the regular axonemal pattern of a central pair of microtubules surrounded by nine doublets enclosed by plasma membrane (Fig. 3, parts 19, 20).

\section{Discussion}

The spermatozoon of Anadara granosa is characteristic of those belonging to the primitive type. Primitive sperm are produced by species that spawn their gametes into the water, where fertilization occurs. Most bivalves including Anadara granosa belong to this category. The nuclei of mature spermatozoa contain dense granular chromatin and are usually invaginated at the anterior pole to varying degrees (Morse and Zardus 1997; Suwanjarat 1998). In this study, the nucleus of mature sperm of Anadara granosa is spherical without anterior invagination; instead, it is sharp-cut and plane at the most anterior. Close to the anterior pole of the nucleus is the acrosome. Acrosome morphology varies in diagnostically important ways in the Bivalvia (Morse and Zardus 1997). It is suggested that the variability in acrosomal morphology may be correlated with the type of fertilization and the thickness of the oocyte vitelline envelope (Junqueira and Carneiro 1980). The structure of the mature acrosome of Anadara granosa, generally, differs slightly in size and shape from those found in many bivalve groups (Popham 1979; Franzen 1983; Hodgson and Burk 1988). Between the acrosome and nucleus is the dense material of subacrosomal substance which is found spread into the deep invagination of the acrosome of this species. In several species, the subacrosomal substance is organized into a more or less completely preformed acrosomal filament or axial rod (Baccetti and Afzelius 1976; Popham 1979). In Saccostrea commercialis, the subacrosomal material comprised an axial rod embedded in a coarsely granular matrix (Healy and Lester 1991). In other species, the subacrosomal substance polymerizes at the time of the acrosome reaction (Baccetti and Afzelius 1976). In this study the subacrosomal substance is dense granular material and no axial rods are found, which is similar to the acrosome of Pecten maximus (Dorange and Le Pennec 1989) and Amusium pleuronectes (Suwanjarat 1998). In the mature sperm of the primitive type, the middle piece contains a number of large mitochondria which are probably formed by the fusion of several smaller ones. In bivalves, the number of mitochondria in the midpiece generally ranges from four to six (Healy 1989). In Anadara granosa five mitochondria are formed around the centrioles similar to the mature sperm of Laternula limicola (Kubo 1977), while the majority of the bivalves have four (Popham 1979; Griffond 1980; Franzen 1983; Dorange and Le Pennec 1989; Suwanjarat 1998), and there are nine in Ocenebra erinacea (Feral 1977). It is obvious that the number of mito- 
chondria in the middle piece of mature spermatozoon are variable among the bivalves and this seems to be a species-specific characteristic.

In primitive sperm of most molluscs, both centrioles are conserved. At the start of spermiogenesis, they are positioned at right angles to each other, the proximal one being oriented perpendicular to the axoneme and the distal one in line with the axoneme. The distal centriole forms the basal body of the flagellum (Morse and Zardus 1997). Deviations from this general pattern are sometimes encountered. For example, in mature sperm of the bivalve Lyonosia ventricosa, the proximal centriole moves to the lateral side of the distal one in such a way that the two centrioles are parallel (Kubo and Ishikawa 1978). In Anadara granosa, the centrioles are positioned at right angles and situated in the posterior of the nucleus. The distal centriole begins to form flagellum in the spermatocyte, which is earlier than in other molluscs. However, a similar appearance has been observed in a number of marine invertebrates with external fertilization, with a flagellum and proacrosomal vesicles common in spermatogonia and spermatocytes (Reunov and Klepal 1997). It has been reported that variation between species at this point appears in the length of the connective strand and thus in the distance between the centrioles (Steiner 1993). In molluscs, the typical sperm processes one flagellum. The axoneme within the flagellum normally consists of a central pair of microtubules surrounded by nine doublets. A few deviations from this general pattern have been reported in molluscs. In this study, the flagellum of Anadara granosa was shown to be a typical axonemal complex of nine plus two microtubules.

From this study it is apparent that Anadara granosa shares the common characteristic features of the primitive spermatozoa. The ultrastructure of sperm and spermiogenesis of Anadara granosa does not differ significantly from the common organization in other bivalves. However, the spermatozoa of most bivalves including this species exhibit their own ultrastructural characteristics. The diversity of Anadara granosa can be seen in the particular arrangement of organelles in the cytoplasm of the early stage of the germ cell, and also in the sperm shape, including the acrosome morphology. Further studies on spermatozoon morphology of other species within the genus may provide a useful systematic tool to help define the species and species groups. The resemblance or distinctive characteristics of some structures or organelles in the developing germ cells can be grouped and described at family level.

Acknowledgements I wish to thank Professor Dr. Waltraud Klepal for the help and the facilities in her electron microscope laboratory. I also thank Dr. Marieluise Weidinger for her excellent technical assistance in transmission electron microscopy. I am grateful to Dr. Alan F. Geater for critical reading of the manuscript. I thank the University of Vienna, the Memorandum of Understanding (MOU) Programme and Prince of Songkla University for financial support of this study.

\section{References}

Afzelius BA (1979) Sperm structure in relation to phylogeny in lower metazoa. In: Fawcett DW, Bedford JM (eds) The spermatozoa. Urban and Schwarzenberg, Baltimore, pp 243-251

Baccetti BA, Afzelius BA (1976) The biology of sperm cell. Krager, Basel

Bardach JE, Ryther JH, McLarney WO (1972) Aquaculture. Wiley Interscience, New York

Broom MJ (1983) Gonad development and spawning in Anadara granosa (L.) (Bivalvia: Arcidae). Aquaculture 30:211-219

Dorange G, Le Pennec M (1989) Ultrastructural characteristics of spermatogenesis in Pecten maximus (Mollusca, Bivalve). Invert Reprod Develop 15:109-117

Feral C (1977) Etude de la spermatogenese typique chez Ocenebra erinacea, Mollusque Gasteropode, Prosobranche. Soc Zool France 102:25-30

Franzen A (1955) Comparative morphological investigation into the spermatogenesis among Mollusca. Zool Bidr Upps 30: $339-456$

Franzen A (1983) Ultrastructural studies of spermatozoa in three bivalve species with notes on evolution of elongated sperm nucleus in primitive spermatozoa. Gamete Res 7:199-214

Griffond B (1980) Etude ultrastructurale de la spermatogenese typique de Viviparus L., Mollusque Gasteropode. Arch Biol 91:445-462

Healy JM (1989) Spermiogenesis and spermatozoa in the relict bivalve genus Neotrigonia: relevance to trigoniod relationships, particularly Unionoidea. Mar Biol 103:73-85

Healy JM, Lester RJG (1991) Sperm ultrastructure in the Australian oyster Saccostrea commercialis (Iredale and Roughley) (Bivalvia: Ostereoidea). J Moll Stud 57:219-224

Hodgson AN, Bernard RTF (1986) Ultrastructure of the sperm and spermatogenesis of three species of Mytilidae (Mollusca, Bivalvia). Gamete Res 15:123-135

Hodgson AN, Bernard PTF (1988) A comparison of the structure of the spermatozoa and spermatogenesis of 16 species of patellid limpets (Mollusca: Gastropoda: Archaeogastropoda). J Morphol 195:205-223

Hodgson CA, Burk RD (1988) Development and larval morphology of the spiny scallop Chlamys hastata. Biol Bull 174: 303-318

Junqueira LC, Carneiro J (1980) Basic histology, 3rd edn. Maruzen Asia PTE, Singapore

Kan-no H (1963) Breeding in the ark Anadara broughtoni (Schrenk) in tank. Bull Tohoku Reg Fish Res Lab 23:108-116

Kim JD, Koo JH (1973) Study on the seedling production of the ark Anadara broughtoni (Schrenk) in tank (1). Bull Fish Res Dev Agency, Korea 11:71-78

Kubo M (1977) The formation of a temporary acrosome in the spermatozoon of Laternula limicola (Bivalvia, Mollusca). J Ultrastruct Res 61:140-148

Kubo M, Ishikawa M (1978) Organizing process of the temporary acrosome in spermatogenesis of the bivalve Lyonosia ventricosa. J Submicrosc Cytol 10:411-421

Maxwell WL (1983) Mollusca. In: Adiyodi KG, Adiyodi RG (eds) Reproductive biology of invertebrates. vol II: spermatogenesis and sperm function. John Wiley, New York, pp 275-319

Morse MP, Zardus JD (1997) Bivalvia. In: Microscopic anatomy of invertebrates, vol 6A: mollusca II. Wiley - Lis, pp 89-95

Popham JD (1974) Comparative morphometrics of the acrosome of the sperm of "externally" and "internally" fertilizing sperms of the shipworms (Teredinidae, Bivalvia, Mollusca). Cell Tissue Res 150:291-297

Popham JD (1979) Comparative spermatozoon morphology and bivalve phylogeny Malacol Rev 2:1-20

Popham JD, Dickson MR, Goddard CK (1974) Ultrastructure study of the mature gametes of two species of Bankia (Mollusca: Teredinidae). Aust J Zool 22:1-12 
Reunov AA, Klepal W (1997) Ultrastructural investigation of spermatogenesis in the nemertine worm Procephalothrix sp. (Palaeonemertini, Anopla). Helgol Meeresunters 51:125-135

Sousa M, Corral L, Azevedo C (1989) Ultrastructural and cytochemical study of spermatogenesis in Scrobicularia plana (Mollusca, Bivalvia). Gamete Res 24:1-9

Steiner SSC (1993) Comparative ultrastructural studies on Scleractinian spermatozoa (Cnidaria, Anthozoa). Zoomorphology 113:129-136
Suwanjarat J (1998) TEM study of the Asian moon scallop (Amusium pleuronectes) spermatogenasis. JEMST 12:95-104

Suwanjarat J, Parnrong S (1990) Reproductive cycles of Anadara granosa L. in Jebilung, Satun Province. Songklan. J Sci Technol 12:341-351

Toral-Barza L, Gomez ED (1985) Reproductive cycle of the cockle Anadara antiquata L. in Calatagon, Batangas, Philippines. J Coastal Res 1:241-245

Communicated by H.-D. Franke 